\title{
Recursos Humanos em Saúde Mental, Álcool e outras Drogas: Diretrizes globais e nas Américas*
}

\author{
Carla Aparecida Arena Ventura ${ }^{1}$
}

(iD) https://orcid.org/0000-0003-0379-913X

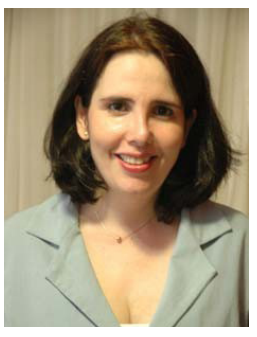

Nas últimas décadas, são observados desequilíbrios e reduções na força de trabalho em saúde e nessa perspectiva, a formação, disponibilidade e qualificação de recursos humanos compõem as prioridades das agendas de saúde global, regional e nacionais.

O Relatório Mundial de Saúde de 2006, "Trabalhando juntos para a Saúde"(1), elaborado pela Organização Mundial da Saúde (OMS), analisou a crise mundial de recursos humanos em saúde e inovou ao apresentar propostas para lidar com problemas da força de trabalho em saúde em dez anos. Dentre as iniciativas resultantes desse movimento, destaca-se a Estratégia Global sobre Recursos Humanos para a Saúde: Força de Trabalho 2030, adotada pela $67^{a}$ Assembleia Geral da $\mathrm{OMS}^{(2)}$, como desdobramento da Declaração Política de Recife sobre Recursos Humanos para a Saúde.

A Estratégia Global determinou como visão acelerar a organização de programas para a cobertura universal de saúde e o atingimento dos Objetivos de Desenvolvimento Sustentável (ODS), assegurando acesso equitativo aos trabalhadores de saúde, por meio do fortalecimento dos sistemas de saúde. Estabeleceu como princípios: promover o direito ao melhor padrão possível de saúde; promover serviços integrados e centrados nas pessoas; promover comunidades engajadas e autônomas; fortalecer os direitos de todos os trabalhadores de saúde, incluindo ambientes de trabalho decente e liberdade contra todos os tipos de discriminação, coerção e violência; além de promover a colaboração e solidariedade internacional, em alinhamento às prioridades nacionais; assegurar práticas éticas de recrutamento e garantir o compromisso político dos países para o cumprimento dessas metas.

Países com distintos níveis de desenvolvimento econômico enfrentam dificuldades para a formação, organização, retenção e atuação da força de trabalho em saúde. Considerando que o trabalho dos profissionais de saúde é essencial para o funcionamento dos sistemas de saúde, o avanço da cobertura dos serviços de saúde e o atingimento do direito à saúde somente serão possíveis por meio de sua disponibilidade, acessibilidade,

\footnotetext{
* A publicação deste artigo na Série Temática "Recursos Humanos em Saúde e Enfermagem" se insere na atividade 2.2 do Termo de Referência 2 do Plano de Trabalho do Centro Colaborador da OPAS/OMS para o Desenvolvimento da Pesquisa em Enfermagem, Brasil.

${ }^{1}$ Universidade de São Paulo, Escola de Enfermagem de Ribeirão Preto, Centro Colaborador da OPAS/OMS para o Desenvolvimento da Pesquisa em Enfermagem, Ribeirão Preto, SP, Brasil.
}

\section{Como citar este artigo}

Ventura CAA. Human Resources in Mental Health, Alcohol and Other Drugs: Global Guidelines and for the American Continent. SMAD, Rev Eletrônica Saúde Mental Álcool Drog. 2021 jul.-set.;17(3):1-3. doi: https://dx.doi.org/10.11606/issn.1806-6976.smad.2021.000188 
aceitabilidade e qualidade do serviço oferecido. Outrossim, a maior disponibilidade de profissionais de saúde não é suficiente por si só. É fundamental que os profissionais de saúde estejam distribuídos de forma equitativa e acessível à população, que desenvolvam as competências necessárias e estejam motivados para oferecer um cuidado de qualidade, que seja adequado às expectativas sócio culturais da população.

A força de trabalho em saúde desempenha papel vital na construção da resiliência das comunidades e sistemas de saúde, para que possam responder aos desafios globais e locais. Contudo, os investimentos na força de trabalho em saúde são ainda escassos, reduzindo a sustentabilidade dos sistemas e da força de trabalho em saúde. Dessa forma, a Estratégia Global estabeleceu opções políticas importantes para os Estados Membros da OMS, visando fomentar o progresso para o atingimento dos ODS, construindo capacidades humanas para implementar esta agenda.

Nas Américas, durante a 29a Conferência Sanitária Pan-Americana, em 2017, os países membros da Organização Pan-Americana de Saúde (OPAS) reafirmaram seu compromisso com o acesso universal à saúde e a cobertura universal de saúde, com base nos Objetivos Regionais para o Desenvolvimento de Recursos Humanos 2007-2015(3), que reafirmou a necessidade de uma correlação entre os perfis de competência dos profissionais de saúde e as estratégias da OMS e OPAS para o desenvolvimento de recursos humanos.

Reconhecem que, apesar do progresso alcançado para o desenvolvimento social e econômico e o fortalecimento dos sistemas de saúde, há ainda muitas iniquidades e exclusão no acesso a serviços apropriados e de qualidade, especialmente para grupos vulneráveis. A situação na região é caracterizada por baixas taxas de retenção de profissionais em áreas rurais, alta mobilidade e migração, condições precárias de trabalho, baixa produtividade e performance. Ainda, mesmo quando os recursos humanos estejam disponíveis, podem não possuir perfil e competências apropriados, uma perspectiva intercultural ou estarem no lugar certo para melhorar a saúde das populações que servem. Em suma, os recursos humanos em saúde na região nem sempre estão alinhados com as necessidades dos sistemas de saúde locais, sendo, portanto, necessárias soluções inovadoras para lidar com os desafios da região.

A estratégia regional se baseia nos princípios do direito à saúde, equidade e solidariedade e no pressuposto de que os recursos humanos em saúde desempenham papel central em lidar progressivamente com as barreiras organizacionais, étnicas e de gênero, para que as comunidades possam ter melhor acesso a serviços de saúde adequados e de qualidade.

Nesse contexto, a área de saúde mental enfrenta os desafios expostos pelos documentos e estratégias supramencionados, assim como problemas no planejamento e treinamento de pessoal. A grande maioria dos países possuem poucos recursos humanos qualificados para atuar na área. Nesse sentido, a saúde mental deveria ser prioridade na agenda de saúde pública dos países.

Nos últimos cinquenta anos, o cuidado em saúde mental tem enfrentado mudanças, com foco na comunidade e na maior integração da saúde mental com o cuidado geral em saúde, com o propósito de lidar com o estigma e discriminação, por meio de abordagens multidisciplinares e colaboração intersetorial com atores não estatais. É fundamental que os países desenvolvam políticas apropriadas para os recursos humanos, adotem estratégias de gestão, com foco em liderança, motivação do pessoal, aumento da retenção, inclusão da saúde mental como componente do currículo dos profissionais de saúde, ou seja, que atuem para a construção de um novo paradigma para a saúde mental(4).

Este número especial da revista SMAD apresenta relevantes contribuições para esta discussão, corroborando a importância de estudos que enfoquem o fortalecimento de recursos humanos na área de saúde mental/álcool e outras drogas.

Esta edição foi organizada como uma demanda do plano de trabalho do Centro Colaborador da OPAS/OMS para o Desenvolvimento da Pesquisa em Enfermagem (atividade 2.2. do Termo de Referência 2), sediado na Escola de Enfermagem de Ribeirão Preto da Universidade de São Paulo, visando apresentar e integrar evidências sobre o desenvolvimento de recursos humanos na área de saúde mental, álcool e outras drogas. Desejamos, assim, que os artigos inspirem ainda mais nossos leitores(as) a desenvolverem pesquisas e estudos inovadores sobre o tema! Uma excelente leitura a todos e todas!

\section{Referências}

1. Organização Mundial da Saúde. Relatório mundial de saúde, 2006: trabalhando juntos pela saúde. Brasília: Ministério da Saúde, OMS; 2007.

2. Organização Mundial de Saúde. Health Workforce 2030: towards a global strategy on human resources for health. Geneva: OMS; 2015. 
3. Pan American Health Organization. 27th Pan American Sanitary Conference 59th Session of the Regional Committee. Regional Goals for Human Resources for Health 2007-2015. In: Final Report. CSP27/FR (Eng.) 5 December 2007. Washington, D.C., USA, 1-5 October 2007 [cited 2016 Jun 10]. Available from: http://www1.paho.org/english/gov/ csp/csp27-fr-e.pdf?ua $=1$

4. World Health Organization. Mental Health - Action Plan 2013-2020 [Internet]. Geneva (SW); World Health Organization; 2013 [cited 2016 Jun 10]. Available from: http://apps.who.int/iris/bitstream/10665/89966/1/9789241506021_eng. pdf?ua $=1$ 